\title{
Re-organisation of oesophago-gastric cancer care in England: progress and remaining challenges
}

\author{
Thomas R Palser ${ }^{1}$, David A Cromwell*1,2, Richard H Hardwick ${ }^{3}$, \\ Stuart A Riley ${ }^{4}$, Kimberley Greenaway ${ }^{5}$, William Allum ${ }^{6}$ and Jan HP van der \\ Meulen ${ }^{1,2}$
}

Address: ${ }^{1}$ Clinical Effectiveness Unit, The Royal College of Surgeons of England, 35-43 Lincoln's Inn Fields, London WC2A 3PE, UK, ${ }^{2} \mathrm{Health}$ Services Research Unit, Department of Public Health \& Policy, London School of Tropical Medicine and Hygiene, Keppel St, London WC1E 7HT, UK, ${ }^{3}$ Cambridge Oesophago-Gastric Centre, Addenbrooke's Hospital, Cambridge University Hospitals NHS Foundation Trust, Hills Road, Cambridge CB2 2QQ, UK, ${ }^{4}$ Department of Gastroenterology, Northern General Hospital, Herries Road, Sheffield, South Yorkshire S5 7AU, UK, ${ }^{5}$ National Clinical Audit Support Program, NHS Information Centre for Health and Social Care, 1 Trevelyan Square, Boar Lane, Leeds, LS1 6AE, UK and ${ }^{6}$ Department of Surgery, The Royal Marsden NHS Foundation Trust, Fulham Road, London SW3 6JJ, UK

Email: Thomas R Palser - tpalser@rcseng.ac.uk; David A Cromwell* - david.cromwell@lshtm.ac.uk; Richard H Hardwick - richard.hardwick@addenbrookes.nhs.uk; Stuart A Riley - Stuart.Riley@sth.nhs.uk; Kimberley Greenaway - Kimberley.Greenaway@ic.nhs.uk; William Allum - wmallum@ hotmail.com; Jan HP van der Meulen - jan.vandermeulen@Ishtm.ac.uk

* Corresponding author

Published: 12 November 2009

BMC Health Services Research 2009, 9:204 doi:10.1 186/1472-6963-9-204

This article is available from: http://www.biomedcentral.com//472-6963/9/204

(C) 2009 Palser et al; licensee BioMed Central Ltd.

This is an Open Access article distributed under the terms of the Creative Commons Attribution License (http://creativecommons.org/licenses/by/2.0), which permits unrestricted use, distribution, and reproduction in any medium, provided the original work is properly cited.
Received: 26 February 2009

Accepted: 12 November 2009

\begin{abstract}
Background: Oesophago-gastric cancer services in England have been extensively reorganised since $200 \mathrm{I}$ to deliver a centralised, specialist-led service. Our aim was to assess how well the National Health Service (NHS) in England met organisational standards for oesophago-gastric cancer care.

Methods: Questionnaires that asked about the provision of staging investigations, curative and palliative treatments and key personnel were sent in September 2007 to the lead clinician for oesophago-gastric cancer at all 30 cancer networks and I56 NHS acute trusts in England.

Results: Responses were received from all networks and $81 \%$ of NHS trusts. All networks provided essential staging investigations and a range of endoscopic palliative therapies. Only 16 of the 30 cancer networks discussed all patients at the specialist multi-disciplinary team meeting and II networks had not fully centralised curative surgery. There was also variation between NHS trusts in the integration of the palliative care team, the availability of nurse specialists and the use of dieticians to provide nutritional support.
\end{abstract}

Conclusion: There has been considerable progress in reforming oesophago-gastric cancer services but the process of reorganisation is still incomplete and regional differences in service provision exist that may lead to variation in patient outcomes. 


\section{Background}

Oesophageal and gastric cancer together represent the third most common cause of cancer death in the United Kingdom [1-3]. The prognosis is often poor with overall 5 -year survival rates in the United Kingdom being approximately $8 \%$ for oesophageal cancer and $14 \%$ for gastric cancer $[1,2]$. The majority of patients present with advanced disease and many also have significant comorbidity and a poor level of overall fitness. As a result, the diseases' management, both curative and palliative, is complex and involves many different professional groups including surgeons, gastroenterologists, oncologists, palliative care physicians, radiologists, nurse specialists and dieticians [4-7].

During the 1990s, it was recognised that oesophago-gastric cancer services in England were fragmented and poorly organised. To overcome these weaknesses, the National Health Services (NHS) Cancer Plan [8] and the Improving Outcomes Guidance in Upper Gastro-Intestinal Cancer [5] set out a reform strategy and a number of specific recommendations. Firstly, all hospitals caring for cancer patients should be integrated into regional cancer networks. Within each network, curative services should be centralised into specialist cancer centres and a system should be established to coordinate care between these centres and other network hospitals (designated local units). Secondly, it was recommended that clinicians within each hospital should work together as a multi-disciplinary team (MDT).

The implementation of this reform strategy has seen oesophago-gastric cancer services undergo an extensive reorganisation. In this paper, we describe the results of a survey of English cancer networks and NHS acute trusts carried out in September 2007 that aimed to investigate the extent to which the reorganisation of oesophago-gastric cancer services had been completed, and to examine variation in the provision of diagnostic, therapeutic and support services. We also discuss these findings with the results of the Cancer Peer Review Programme carried out by the UK Department of Health between 2004 and 2007. The survey was performed as part of the National Oesophago-Gastric Cancer Audit, details of which can be found in its first annual report [9].

\section{Methods}

Data on the organisation of oesophago-gastric cancer services were collected using two different questionnaires. The first contained questions that focused on the organisation of services within the cancer networks [see Additional file 1]. Networks are responsible for developing and planning all aspects of NHS cancer services within their region, including the process of centralisation. This requires coordinating the allocation of resources and establishing referral pathways between NHS acute trusts as well as other providers. The second questionnaire contained questions about the individual characteristics of services within the individual NHS trusts, focussing on the availability of key health professionals and the delivery of specific aspects of care [see Additional file 2]. Questions in both questionnaires were based on the recommendations in UK guidelines on the organisation of oesophago-gastric cancer services $[5,6,10,11]$ (Table 1 ) and covered issues previously identified as essential for high-quality care [9].

A database of English cancer networks and NHS acute trusts was prepared by combining information from various sources, including the Cancer Services Collaborative Improvement Partnership and the National Clinical Audit Support Program. Each network and NHS trust was then contacted to confirm the name and position of the lead clinician for oesophago-gastric cancer. The questionnaires were sent to these lead clinicians in September 2007 and non-responders were followed up by email and telephone.

\section{Results}

Responses were received from all 30 cancer networks and from 38 of the 44 specialist cancer centres $(84 \%)$ and from 88 of the 112 local units (79\%). The structure of the networks are summarised in Table 2.

\section{Cancer networks}

The centralisation of oesophago-gastric curative cancer surgery was reported as still ongoing in 11 of the 30 networks. In four of the eleven, this involved centralising the work of one remaining unit. Services still required major restructuring in the other seven networks, with the lead clinicians in four of these reporting that the timescale for completion of this work was unclear.

The cancer networks identified 59 acute trusts that performed curative surgery for oesophago-gastric cancer. Of these, $14(24 \%)$ were local units and one network reported that some patients received surgery in a Welsh cancer centre. All of the 45 specialist cancer centres and seven local units performed both oesophageal and gastric surgery. The seven other local units performed gastric surgery only. There were 152 surgeons working at these 59 acute trusts; $137(90 \%)$ were upper gastrointestinal surgeons and $15(10 \%)$ were thoracic surgeons (who worked at ten of the centres). The number of surgeons working at individual trusts varied from one to five (Table 3). Seven local units had a single surgeon and 53\% of centres had three surgeons or more. Visiting surgeons based at local units carried out curative surgery in 18 specialist cancer centres. 
Table I: Published standards on which the survey questionnaires were based

\begin{tabular}{|c|c|}
\hline Network questionnaire & Trust questionnaire \\
\hline $\begin{array}{l}\text { I. Treatment for patients with oesophageal cancer should be the } \\
\text { responsibility of Specialist Oesophago-gastric Cancer Teams based in } \\
\text { Cancer Units or Cancer Centres which would normally serve } \\
\text { populations of at least one million. (IOG, p } 45 \text { ) }\end{array}$ & $\begin{array}{l}\text { I. The specialist palliative care team should be multi-professional, and } \\
\text { should, as a minimum, include a palliative care physician and palliative } \\
\text { care nurse specialists. (IOG, p6I) }\end{array}$ \\
\hline $\begin{array}{l}\text { 2. There should be } 24 \text {-hour on-call consultant specialist surgical cover } \\
\text { for postoperative care. Note: To achieve this measure at least } 3 \\
\text { specialist consultant surgeons per team would be needed. } \\
\text { (MCS, measure } 2 \mathrm{~F}-227)\end{array}$ & $\begin{array}{l}\text { 2. A palliative care specialist should be a member of the Specialist } \\
\text { Oesophago-Gastric Cancer Team and the Local Upper Gastro-intestinal } \\
\text { Cancer Care Team. (IOG, p29-3I) }\end{array}$ \\
\hline $\begin{array}{l}\text { 3. The stage and spread of the cancer should be assessed using } \\
\text { computed tomography (CT) or magnetic resonance scanning. If the } \\
\text { patient is sufficiently fit to undergo radical treatment and imaging } \\
\text { produces no evidence of widespread or metastatic disease, endoscopic } \\
\text { ultrasound (EUS) should be used to estimate the depth of tumour } \\
\text { penetration. If this also suggests that radical treatment could be } \\
\text { successful, patients whose tumours could involve the peritoneal cavity } \\
\text { should proceed to laparoscopy. (IOG, p37) }\end{array}$ & $\begin{array}{l}\text { 3. From the time of assessment, each patient should have access to a } \\
\text { named clinical nurse specialist who can offer support and continuity of } \\
\text { care. (IOG, p32) }\end{array}$ \\
\hline $\begin{array}{l}\text { 4. Laser or photodynamic therapy should be used for initial control of } \\
\text { obstructive symptoms caused by exophytic tumours in the oesophagus. } \\
\text { Partially covered self-expanding metal stents should be used to control } \\
\text { obstructive oesophageal symptoms either following or instead of laser } \\
\text { therapy, depending on the availability of local expertise. (SIGN, p33-35) }\end{array}$ & $\begin{array}{l}\text { 4. Specialist advice should be available from a dietician. This should focus } \\
\text { on helping patients to achieve adequate nutrition. Patients who have } \\
\text { undergone surgery for oesophageal or gastric cancer should be given } \\
\text { guidance to help them deal with post-surgical syndromes which can } \\
\text { cause problems with eating. (IOG, p2I-22) }\end{array}$ \\
\hline $\begin{array}{l}\text { 5. Palliative chemotherapy should start within } 2 \text { weeks and ideally within } \\
48 \text { hours, depending on symptom severity. Chemotherapy with curative } \\
\text { or adjuvant intent should start within } 3 \text { weeks and ideally within I week. } \\
\text { Urgent radiotherapy, e.g., for spinal cord compression or superior vena } \\
\text { cava obstruction, should start within } 24 \text { hours of referral. Palliative } \\
\text { radiotherapy should start within } 2 \text { weeks and ideally within } 48 \text { hours, } \\
\text { depending on symptom severity. Radical radiotherapy should start } \\
\text { within } 4 \text { weeks and ideally within } 2 \text { weeks. (RCR) }\end{array}$ & $\begin{array}{l}\text { 5. All patients should be screened using a validated screening tool to } \\
\text { assess nutritional risk. (SIGN, p24) }\end{array}$ \\
\hline
\end{tabular}

KEY to references:

SIGN = The Scottish Intercollegiate Guidelines Network (2006) [10]; IOG = Department of Health (200I) [5]; MCS = Department of Health

(2004) [6]; RCR = The Royal College of Radiologists (2003) [II]

In 16 of the 30 networks, all patients were discussed at a specialist MDT meeting (i.e. an MDT meeting in a specialist cancer centre), while in the remaining networks only patients who were felt to require specialist input were discussed at these specialist MDT meetings.

The core staging investigations (CT scan, endoscopic ultrasound (EUS), laparoscopy) were available in all 30 networks, but access to EUS fine needle aspiration, PET, and PET-CT scan was variable (Table 4 ). The networks differed in terms of whether all or selected patients underwent particular investigations. Where investigations were performed in selected cases, the selections were based on clinical considerations rather than on patients' geographical location within the network.

Palliative treatment in the form of endoluminal stents and argon beam coagulation was available in all 30 networks, laser ablation or photodynamic therapy in 18 , and brachytherapy in 16. All but two networks could provide endoscopic palliative therapy within two weeks of the decision to treat. Similarly, access to chemotherapy (both palliative and curative) could be provided within the same timeframe by 27 networks and to radiotherapy by 25 .

\section{NHS acute trusts}

106 of the 126 responding trusts ( $84 \%$ ) had palliative care teams that included both a palliative medicine consultant and a palliative nurse specialist. Integration of palliative care into the multidisciplinary process was variable, with no member of the palliative care team routinely attending the MDT meetings at 10 of the 38 responding specialist cancer centres (26\%) and 26 of the 88 local units $(30 \%)$.

The number of clinical nurse specialists (CNS) varied between trusts. All 38 responding cancer centres had at least one full-time or two part-time CNS and 18 (47\%) had two or three full-time CNS. Local units had fewer nurse specialists. Of the 88 responding local units, 15 $(17 \%)$ had only one part-time CNS and nine had none at all.

All 38 responding specialist cancer centres and 83 of the 88 local units $(94 \%)$ were able to provide dietician support. However, trusts differed in the groups of patients for whom dietician support was available and in the method of nutritional assessment made before patients began their treatment (Table 5). In particular, 33 of the 126 responding trusts $(26 \%)$ had no dietician support for 
Table 2: Organisation of NHS oesophago-gastric cancer services in England at the time of the survey

\begin{tabular}{|c|c|c|c|c|c|}
\hline \multirow[t]{2}{*}{ English region } & \multirow[t]{2}{*}{ Cancer network } & \multicolumn{3}{|c|}{ Number of NHS acute trusts } & \multirow{2}{*}{$\begin{array}{r}\text { Number of responses from NHS } \\
\text { trusts }\end{array}$} \\
\hline & & Cancer Centres & Local Units & Total & \\
\hline North & Lancashire and South Cumbria & 1 & 3 & 4 & 4 \\
\hline North & Greater Manchester and Cheshire & 3 & 9 & 12 & 11 \\
\hline North & Merseyside and Cheshire & 2 & 7 & 9 & 6 \\
\hline North & Yorkshire & 2 & 5 & 7 & 7 \\
\hline North & Humber and Yorkshire Coast & 1 & 2 & 3 & 3 \\
\hline North & North of England & 2 & 7 & 9 & 8 \\
\hline East Midlands & North Trent & 2 & 3 & 5 & 5 \\
\hline East Midlands & Arden & I & 2 & 3 & 3 \\
\hline East Midlands & Mid Trent & 1 & 2 & 3 & 2 \\
\hline East Midlands & Derby/Burton & 1 & 1 & 2 & 2 \\
\hline East Midlands & $\begin{array}{l}\text { Leicestershire, Northamptonshire and } \\
\text { Rutland }\end{array}$ & 2 & 1 & 3 & 3 \\
\hline West Midlands & Pan Birmingham & 2 & 2 & 4 & 3 \\
\hline West Midlands & 3 Counties & 1 & 2 & 3 & 3 \\
\hline West Midlands & Greater Midlands & 2 & 3 & 5 & 5 \\
\hline East of England & Mount Vernon & 2 & 1 & 3 & 2 \\
\hline East of England & Thames Valley & 2 & 4 & 6 & 6 \\
\hline East of England & Anglia & 2 & 7 & 9 & 5 \\
\hline East of England & Essex & 1 & 4 & 5 & 2 \\
\hline London & West London & 1 & 6 & 7 & 4 \\
\hline London & North London & 1 & 5 & 6 & 2 \\
\hline London & North East London & 2 & 3 & 5 & 5 \\
\hline London & South East London & 1 & 5 & 6 & 4 \\
\hline London & South West London & 1 & 4 & 5 & 3 \\
\hline South East & Central South Coast & 2 & 5 & 7 & 5 \\
\hline South East & Surrey, West Sussex and Hampshire & 1 & 3 & 4 & 4 \\
\hline South East & Sussex & 1 & 2 & 3 & 2 \\
\hline South East & Kent and Medway & 1 & 3 & 4 & 3 \\
\hline South West & Peninsula & 1 & 4 & 5 & 5 \\
\hline South West & Dorset & 1 & 2 & 3 & 3 \\
\hline South West & Avon, Somerset and Wiltshire & 1 & 5 & 6 & 6 \\
\hline
\end{tabular}

their surgical inpatients and 41 (33\%) did not perform any formal nutritional assessment before starting treatment.

\section{Discussion}

Since the publication of the Improving Outcomes Guidance [5], oesophago-gastric cancer services in England have made considerable progress in developing a central- ised, specialist service. We found that, in September 2007, all NHS acute trusts were organised into cancer networks and patients in all networks had access to the core staging investigations as well as to a range of palliative treatments. Coinciding with this reorganisation, the overall survival of patients with oesophago-gastric cancer has improved, with 1-year survival increasing from $30 \%$ to $37 \%$ between 1998 and 2005 [9]. However, we found that some compo-

Table 3: Number of surgeons performing oesophago-gastric curative surgery within NHS acute trusts identified by the 30 English cancer networks as providing this service

\begin{tabular}{|c|c|c|c|c|c|}
\hline & \multicolumn{5}{|c|}{ Number of surgeons per trust } \\
\hline & $\mathbf{I}$ & 2 & 3 & 4 & 5 \\
\hline Cancer centres $(n=45)$ & $\begin{array}{c}0 \\
(0 \%)\end{array}$ & $\begin{array}{c}21 \\
(47 \%)\end{array}$ & $\begin{array}{c}14 \\
(31 \%)\end{array}$ & $\begin{array}{c}3 \\
(7 \%)\end{array}$ & $\begin{array}{c}7 \\
(16 \%)\end{array}$ \\
\hline $\begin{array}{l}\text { Local units providing oesophageal } \\
\text { and gastric surgery }(n=7)\end{array}$ & $\begin{array}{c}2 \\
(29 \%)\end{array}$ & $\begin{array}{c}5 \\
(71 \%)\end{array}$ & 0 & 0 & 0 \\
\hline $\begin{array}{l}\text { Local units providing gastric surgery } \\
(\mathrm{n}=7)\end{array}$ & $\begin{array}{c}5 \\
(71 \%)\end{array}$ & $\begin{array}{c}2 \\
(29 \%)\end{array}$ & 0 & 0 & 0 \\
\hline
\end{tabular}


Table 4: Reported availability of staging investigations in the 30 English cancer networks

\begin{tabular}{|c|c|c|c|c|c|}
\hline \multirow[t]{2}{*}{ Investigation } & \multirow[b]{2}{*}{ Tumour site } & \multicolumn{4}{|c|}{ Patients on whom the investigation is performed } \\
\hline & & In all patients & In selected patients & None & Missing values \\
\hline \multirow[t]{3}{*}{ CT scan } & Oesophageal & $28(93 \%)$ & $2(7 \%)$ & & \\
\hline & Junctional & $28(93 \%)$ & $2(7 \%)$ & & \\
\hline & Gastric & $28(93 \%)$ & $2(7 \%)$ & & \\
\hline Endoscopic & Oesophageal & $17(57 \%)$ & $13(43 \%)$ & & \\
\hline \multirow[t]{2}{*}{ Ultrasound (EUS) } & Junctional & $16(53 \%)$ & $14(47 \%)$ & & \\
\hline & Gastric & $3(10 \%)$ & $22(73 \%)$ & $5(17 \%)$ & \\
\hline Staging & Oesophageal & $2(7 \%)$ & $25(86 \%)$ & $2(7 \%)$ & I \\
\hline \multirow[t]{2}{*}{ Laparoscopy } & Junctional & $12(4 \mid \%)$ & $17(59 \%)$ & & I \\
\hline & Gastric & $19(66 \%)$ & $10(34 \%)$ & & 1 \\
\hline EUS Fine & Oesophageal & $3(10 \%)$ & $20(67 \%)$ & $7(20 \%)$ & \\
\hline Needle & Junctional & $3(10 \%)$ & $20(67 \%)$ & 7 (20\%) & \\
\hline Aspiration & Gastric & $2(7 \%)$ & $17(57 \%)$ & II (37\%) & \\
\hline \multirow[t]{3}{*}{ PET Scan } & Oesophageal & $10(33 \%)$ & 17 (57\%) & $3(10 \%)$ & \\
\hline & Junctional & $8(4 \%)$ & $19(63 \%)$ & $3(10 \%)$ & \\
\hline & Gastric & $2(7 \%)$ & $16(53 \%)$ & $11(37 \%)$ & \\
\hline \multirow[t]{3}{*}{ PET-CT } & Oesophageal & $7(23 \%)$ & $21(70 \%)$ & $2(7 \%)$ & \\
\hline & Junctional & $6(20 \%)$ & $22(73 \%)$ & $2(7 \%)$ & \\
\hline & Gastric & I (3\%) & $19(63 \%)$ & $10(33 \%)$ & \\
\hline
\end{tabular}

nents of this reorganisation were not yet complete. The centralisation of curative surgery was still in progress in 11 of the 30 cancer networks. Fourteen local units were still performing curative surgery and in seven of these, this was being performed by a single surgeon. Also, in only 16 networks were all patients discussed at a specialist MDT meeting. Moreover, palliative care teams were not fully represented in about a quarter of the multidisciplinary teams and some local units did not have a clinical nurse specialist.

The response rate to our questionnaires was high which strengthens the representativeness of our findings. There are three limitations to the study. Firstly, this was a crosssectional study so the results do not provide evidence of change over time. Secondly, respondents provided selfreported data and we cannot exclude "social desirability bias" given that the lead clinicians may have wanted to give favourable answers. However, the likely impact of this bias is small because most questions addressed facts rather than perceptions.

Thirdly, the study examined the facilities and policy of each network, not what actually happens to patients. For example, while the policy in each network recommended that all patients being considered for curative treatment

Table 5: Provision of nutritional support to oesophago-gastric cancer patients by the 126 NHS acute trusts who responded to the questionnaire

\begin{tabular}{lcc}
\hline & $\begin{array}{c}\text { Cancer centres } \\
(\mathbf{n = 3 8 )}\end{array}$ & $\begin{array}{c}\text { Local units } \\
(\mathbf{n}=\mathbf{8 8})\end{array}$ \\
\hline Patients who have access to a dietician for specialist nutritional advice & $28(74 \%)$ \\
$\quad$ Surgical inpatients & $34(89 \%)$ \\
All other Oesophago-Gastric cancer inpatients & $32(84 \%)$ & 0 \\
Outpatients & 0 & $75(85 \%)$ \\
No specialist support available & $5(62 \%)$ \\
\hline Methods of formal nutritional assessment prior to treatment & $9(24 \%)$ \\
No formal assessment & $26(68 \%)$ \\
Dietician assessment & $3(8 \%)$ \\
Formal screening instrument & $32(36 \%)$ \\
(e.g. MUST score, Nutritional Risk Index) & $43(49 \%)$ \\
\hline
\end{tabular}


should have a CT scan, the levels of compliance within networks were unknown. Routine activity data could be used to describe progress in centralisation, but more detailed evaluation of processes such as disease staging requires prospective data collection. The National Oesophago-Gastric Cancer Audit will assess the process and outcomes of the care received by patients with this cancer in England and Wales [9].

The results of this "snapshot" survey confirm and complement those of the National Cancer Peer Review Programme that included visits to all cancer networks in England between November 2004 and March 2007 [12]. The Peer Review programme reported that overall compliance with the upper gastro-intestinal performance measures was $70 \%$; compliance with a selected number of measures is shown in Table 6. Our results are more specific because the Peer Review process examined upper-gastrointestinal (upper GI) cancer services, which grouped oesophago-gastric cancer together with liver, pancreatic and biliary tract cancer.

Peer Review found that the performance of upper GI cancer services was often worse than for other cancer sites. For example, the overall compliance rate of $70 \%$ was below that of breast, colorectal, lung and gynaecological cancer (77\%, 77\%, 73\% and $75 \%$, respectively). Similarly, attendance at the MDT meetings was the worst for any cancer site except lung with the core MDT membership present at less than half of the meetings ( $46 \%$ for centres and 33\% for units). This compares to breast $(77 \%)$, colorectal $(58 \%)$ and gynaecology ( $83 \%$ for centres and $45 \%$ for local units). As in our survey, workforce issues were flagged up, especially with respect to the provision of clinical nurse specialists and palliative care teams. Overall upper GI cancer had the worst provision of nurse specialists of any cancer site. Compared to other services involved in the care of all cancer sites (such as oncology, radiology, etc.), specialist palliative care had the lowest overall level of compliance on the performance measures.

The Peer Review Programme was undertaken over a three year period while networks were reorganising their services. The reorganisation was supposed to be complete by the end of 2007 and this may be one reason why Peer Review found variation in how well the networks complied with the IOG recommendations. Our survey builds on Peer Review because it took place shortly before the deadline for full reorganisation. It is concerning that we found significant variation between networks in their provision of services, and that many had still not completed their reorganisation. It is also concerning that a minority were unable to give a date for completion.

The variation in service provision that we observed has implications for patient care and highlights several areas where improvements should be made. Firstly, there is good evidence that postoperative mortality is lower $[13,14]$ and long-term survival is higher [15-17] if curative surgery is performed by high-volume specialist surgical teams. Over a third of the cancer networks had not completed the centralisation of curative surgery and just under half of NHS trusts were not providing 24-hour specialist consultant surgical cover. Of particular concern are the seven local units were still providing curative surgery with just one surgeon. There is a high-risk of complications after curative surgery and, for high quality postoperative care, surgeons with specialist knowledge and experience need to be continuously available.

Secondly, the provision of palliative care services, specialist nurses and nutritional support was variable and in a proportion of NHS trusts was insufficient. Studies have shown that patients with oesophago-gastric cancer require

Table 6: Key findings of the 2004 - 2007 Peer Review Programme of Upper Gastrointestinal Cancer services in English NHS acute trusts [12].

\begin{tabular}{|c|c|c|}
\hline Aspect of care & Peer Review results & \\
\hline Referral pathways & $\begin{array}{l}55 \% \text { of the networks had referral guidelines agreed } \\
\text { for diagnostic referral to secondary care }\end{array}$ & $\begin{array}{l}49 \% \text { of the networks had guidelines agreed for referrals } \\
\text { from secondary to tertiary care. }\end{array}$ \\
\hline Network structure & $\begin{array}{l}\text { There were significant gaps across all cancer sites in } \\
\text { provision of oncologists, pathologists, radiologists, } \\
\text { palliative medicine consultants and clinical nurse } \\
\text { specialists. }\end{array}$ & $\begin{array}{l}37 \% \text { of networks had specialist surgical teams with a } 24- \\
\text { hour on-call rota (i.e. contained a minimum of } 3 \\
\text { surgeons). There was wide regional variation in this from } \\
13 \% \text { (East) to } 60 \% \text { (South). }\end{array}$ \\
\hline MDT structure & $\begin{array}{l}\text { Units and centres had established their core MDTs } \\
\text { in almost } 100 \% \text { of networks. Cover arrangements } \\
\text { for core members (in case of annual leave etc) } \\
\text { were in place overall in } 58 \% \text { of centres and } 44 \% \text { of } \\
\text { units. }\end{array}$ & $\begin{array}{l}46 \% \text { of cancer centres and } 33 \% \text { of local units achieved } \\
\text { the standard of core members attending half of the MDT } \\
\text { meetings }\end{array}$ \\
\hline Clinical Nurse Specialist provision & $\begin{array}{l}\text { The number of clinical nurse specialists per MDT } \\
\text { was } 1.4 \text { for centres and } 0.85 \text { for units. }\end{array}$ & $\begin{array}{l}\text { There was no clinical nurse specialist cover in } 14 \% \text { of } \\
\text { cancer centres and } 31 \% \text { of local units, problems with } \\
\text { workload and cover were reported in more than } 20 \\
\text { centres and } 30 \text { units. }\end{array}$ \\
\hline
\end{tabular}


intensive support due to their poor quality of life and high level of symptoms $[18,19]$. There is also evidence that shows that patients who are malnourished have reduced survival, a worse quality of life $[20,21]$, lower rates of completion of oncology treatment $[22,23]$ and a higher rate of postoperative complications $[22,23]$. Nutritional support has been shown to reduce the impact of malnutrition and improve many of these outcomes [24]. A quarter of specialist centres do not formally assess their patients' nutritional status (either by dietician assessment or by a validated screening tool) before starting treatment. Simple tests such as the Nutritional Risk Index can be rapidly carried out by any doctor or nurse in the outpatients department and if performed on every patient could have a meaningful impact on their care.

Thirdly, although overall access to invasive palliative techniques was good with rapid access to stents and argon ablation therapy being available in all networks, access to other modalities was poor. Patients had to wait longer than 2 weeks for palliative chemotherapy in three of the thirty networks and for palliative radiotherapy in five networks. Brachytherapy was only available in 16 networks despite the fact that, compared to endoluminal stents, research has shown it to have fewer side-effects and provide better palliation in patients with an expected survival of greater than three months [25].

Finally, the Improving Outcomes Guidance recommended that all patients should be discussed by the specialist MDT [5]. The survey found that this occurs in 16 networks (53\%). However, each network was also recommended to develop clinical guidelines on the selection of patients for referral to the specialist team [5]. The Peer Review Programme observed that these guidelines were in place in $71 \%$ of networks [11]. Consequently, not all patients are necessarily receiving the benefit of specialist experience. Processes need to be established so that each patient, irrespective of stage of disease or comorbidity, is evaluated by the network specialist teams, either by formal referral to the specialist MDT meeting or by discussion with a member of the specialist MDT.

\section{Conclusion}

Although considerable progress has been made in transforming oesophago-gastric cancer care into a specialist, multi-disciplinary service, further improvements are necessary. Action is required to rectify the deficits in the provision of surgery, palliative care, clinical nurse specialists and nutritional support. Some of this depends on the further allocation of scarce resources but some aspects, such as ensuring all patients are discussed with a member of the specialist multidisciplinary team and are screened for malnutrition, can be improved by relatively simple changes in practice.

\section{Competing interests}

The authors declare that they have no competing interests.

\section{Authors' contributions}

DC, RHH, SAR and JvdM conceived the study; TP and DC designed the survey and questionnaires, with revisions suggested by RHH, SAR, KG, WA and JvdM; TP and DC conducted the statistical analyses and wrote the manuscript; RHH, SAR, KG, WA and JvdM commented on drafts; all authors read and approved the final manuscript.

\section{Additional material}

\section{Additional file 1}

Cancer network questionnaire. The survey questionnaire sent to cancer network lead clinicians and which contained questions related to the organisation of cancer services within the network.

Click here for file

[http://www.biomedcentral.com/content/supplementary/14726963-9-204-S1.doc]

\section{Additional file 2}

NHS trust questionnaire. The survey questionnaire sent to the lead clinician at each NHS trust and which contained questions about their hospital services.

Click here for file

[http://www.biomedcentral.com/content/supplementary/14726963-9-204-S2.doc]

\section{Acknowledgements}

We would like to thank Clare Bailey, Andrew Pine and Dee Wyke of the National Clinical Audit Support Program for their help in distributing and administering the questionnaire. We would also like to thank Steve Dean for his contribution to the Audit. The results of the Peer Review Programme were reproduced with permission.

The National Oesophago-Gastric Cancer Audit is being carried out by the Association of Upper Gastro-Intestinal Surgeons (AUGIS), the British Society of Gastroenterology (BSG), the National Clinical Audit Support Program (NCASP) of The Information Centre for health and social care (IC) and the Clinical Effectiveness Unit of The Royal College of Surgeons of England.

Funding

The National Oesophago-Gastric Cancer Audit was funded by the Healthcare Commission.

\section{References}

I. Cancer Research UK Statistical Information Team: UK Oesophageal Cancer Statistics for 2007. [http://info.cancerresear chuk.org/cancerstats/types/oesophagus/?a=544I]. Accessed I Feb 2008

2. Cancer Research UK Statistical Information Team: UK Stomach Cancer Mortality Statistics for 2007. [http://info.cancerresear chuk.org/cancerstats/types/stomach/mortality/]. Accessed I Feb 2008

3. Office for National Statistics: Mortality Statistics: cause. Review of the Registrar General on deaths by cause, sex and age, in England and Wales, in 2005 (series DH2 No 32) London: Her Majesty's Stationary Office; 2006. 
4. Allum WH, Griffin SM, Watson A, Colin-Jones D: Guidelines for the management of oesophageal and gastric cancer. Gut 2002, 50(Suppl 5):vl-23.

5. Department of Health: Guidance on Commissioning Cancer Services: Improving Outcomes in Upper Gastro-Intestinal Cancers: The Manual London: Department of Health; 200I.

6. The Scottish Intercollegiate Guidelines Network: SIGN 87 - Management of oesophageal and gastric cancer. A National Clinical guideline Edinburgh: The Scottish Intercollegiate Guidelines Network; 2006.

7. Viklund $P$, Lagergren J: A care pathway for patients with oesophageal cancer. Eur J Cancer Care (Engl) 2007, 16:533-8.

8. Department of Health: The NHS Cancer Plan: A Plan for Investment, a plan for reform London: Her Majesty's Stationary Office; 2000.

9. Palser T, Cromwell D, Meulen J van der, Hardwick RH, Riley S, Greenaway K, Dean S: The National Oesophago-Gastric Cancer Audit. An audit of the care received by people with Oesophago-gastric Cancer in England and Wales. First Annual Report 2008 London: NHS Information Centre; 2008.

10. Department of Health: Manual for Cancer Services London: Her Majesty's Stationary Office; 2004.

1I. The Royal College of Radiologists: Good Practice Guide for Clinical Oncologists 2nd edition. London: The Royal College of Radiologists; 2003.

12. National Cancer Action Team: National Cancer Peer Review Programme 2004 - 2007. National Report. An Overview of the Findings from the Second National Round of Peer Reviews of Cancer Services in England London: National Cancer Action Team; 2008.

13. Halm EA, Lee C, Chassin MR: Is volume related to outcome in health care? A systematic review and methodologic critique of the literature. Ann Intern Med 2002, I 37:5 I I-20.

14. Killeen SD, O'Sullivan MJ, Coffey JC, Kirwan WO, Redmond HP: Provider volume and outcomes for oncological procedure. $\mathrm{Br} J$ Surg 2005, 92:389-402.

15. Bachmann MO, Alderson D, Edwards D, Wotton S, Bedford C, Peters TJ, Harvey IM: Cohort study in South and West England of the influence of specialization on the management and outcome of patients with oesophageal and gastric cancers. BrJ Surg 2002, 89:914-22.

16. Birkmeyer JD, Sun Y, Wong SL, Stukel TA: Hospital volume and late survival after cancer surgery. Ann Surg 2007, 245:777-83.

17. Wenner J, Zilling T, Bladstrom A, Alvegard TA: The influence of surgical volume on hospital mortality and 5 -year survival for carcinoma of the oesophagus and gastric cardia. Anticancer Res 2005, 25:419-24.

18. Blazeby JM, Farndon JR, Donovan J, Alderson D: A prospective longitudinal study examining the quality of life of patients with esophageal carcinoma. Cancer 2000, 88: 178I-7.

19. Blazeby JM, Sanford E, Falk SJ, Alderson D, Donovan JL: Healthrelated quality of life during neoadjuvant treatment and surgery for localized esophageal carcinoma. Cancer 2005, 103:179|-9.

20. Nourissat A, Vasson MP, Merrouche Y, Bouteloup C, Goutte M, Mille $D$, Jacquin JP, Collard O, Michaud P, Chauvin F: Relationship between nutritional status and quality of life in patients with cancer. Eur J Cancer 2008, 44: I 238-42.

21. Ravasco P, Monteiro-Grillo I, Vidal PM, Camilo ME: Cancer: disease and nutrition are key determinants of patients' quality of life. Support Care Cancer 2004, 1 2:246-52.

22. Andreyev HJ, Norman AR, Oates J, Cunningham D: Why do patients with weight loss have a worse outcome when undergoing chemotherapy for gastrointestinal malignancies? Eur J Cancer 1998, 34:503-9.

23. Odelli C, Burgess D, Bateman L, Hughes A, Ackland S, Gillies J, Collins CE: Nutrition support improves patient outcomes, treatment tolerance and admission characteristics in oesophageal cancer. Clin Oncol (R Coll Radiol) 2005, 17:639-45.

24. Isenring EA, Capra S, Bauer JD: Nutrition intervention is beneficial in oncology outpatients receiving radiotherapy to the gastrointestinal or head and neck area. Br J Cancer 2004, 9I:447-52.

25. Homs MY, Steyerberg EW, Eijkenboom WM, Tilanus HW, Stalpers LJ, Bartelsman JF, van Lanschot J], Wijrdeman HK, Mulder C], Reinders JG, Boot H, Aleman BM, Kuipers EJ, Siersema PD: Single-dose brachytherapy versus metal stent placement for the palliation of dysphagia from oesophageal cancer: multicentre randomised trial. Lancet 2004, 364(9444): I497-504.

\section{Pre-publication history}

The pre-publication history for this paper can be accessed here:

http://www.biomedcentral.com/1472-6963/9/204/pre pub
Publish with Bio Med Central and every scientist can read your work free of charge

"BioMed Central will be the most significant development for disseminating the results of biomedical research in our lifetime. "

Sir Paul Nurse, Cancer Research UK

Your research papers will be:

- available free of charge to the entire biomedical community

- peer reviewed and published immediately upon acceptance

- cited in PubMed and archived on PubMed Central

- yours - you keep the copyright
BioMedcentral 